\title{
COMPARISON STUDY BETWEEN THEORETICAL ANALYSIS AND ARTIFICIAL NEURAL NETWORK OF THE CAPILLARY TUBE
}

\author{
Basim Freegah $^{1 *}$, Ammar A. Hussain ${ }^{1}$, Ahmed Ramadhan Al-Obaidi ${ }^{1}$
}

\begin{abstract}
The main purpose of expansion devices is reduced the higher pressure of the working fluid from the condenser pressure to the evaporator pressure. There are several kinds of expansion devices, one of these types is capillary tube which is common utilized in small size refrigeration systems. In this work, the effect of the diameter of capillary tube and mass flow rate of the refrigerant on the physical properties of the refrigerant within the capillary tube have been conducted. Moreover, an artificial neural network (ANN) technique has been utilized in order to clarify the possibility of applying this theory to the effect of such parameters on the results of the capillary tube. The study has been shown that there is a very good agreement between experimental and numerical results. The diameter and mass flow rate have impact on the length of the capillary tube, increase diameter leads to increase the capillary tube length while increase mass flow rate leads to decrease the length. Furthermore, the results shown that ANN technique can be employed to study the effect of such as parameters that considered in this on length of capillary tube. So, it can be using latter technique with accuracy $95 \%$.
\end{abstract}

\section{Keywords: Capillary Tube, Refrigerant Cycle, Physical Properties of Refrigerant, ANN Technique}

\section{INTRODUCTION}

In order to maintain on constant pressure difference of refrigeration system between the evaporator and the condenser, expansion device has been using. One of expansion devices is capillary tube which is using to reducing the high pressure to low pressure in small the air conditioning and the refrigeration systems. Many researchers have been tried to better understand for parameters that have effect on the behavior of the refrigerant within the capillary tube and hence on the dimensions of the capillary tube. Kasuba et. al. [1] conducted theoretical study in order to obtain on optimum dimensions of the capillary tube with various refrigerants as working fluid for small air conditioner system. R22, R410A and R407c have been used as working fluid in the present study. The results have been shown that at same boundary conditions, the length of capillary tube is same for R407c and R22. Whiles, the length of capillary for R410A longer than other refrigerants. The effect of Nano-refrigerant within the capillary tube on the performance of vapor refrigeration system has been studied numerically (CFD) by Oluseyi et. al. [2]. Two types of refrigerant as working fluid have been used, traditional one was (CuR134a) while, new one was (Cu600a). the results have been shown that a CFD tool/method can be used to examine the impact of such as working fluid within the capillary tube. A homogenous model to analysis a refrigerant flow within a spiral adiabatic capillary tube has been developed by M.K. Mittal et. al. [3]. They were studied the influence of spiral pitch on length of capillary tube and refrigerant mass flow rate for two kinds of refrigerant (R-22 \& R-407C) as working fluid. They reported that the properties of flow for both refrigerant are almost similar for a given sub cooling degree and pressure of condenser at the inlet of capillary tube.

Wang et al. [4] numerically simulated the adiabatic capillary tubes coiled in systems of $\mathrm{CO} 2$ transcritical containing the metastable flow. They found that using Churchill and Lin correlations model can provide $1.8 \%$ more than for $\mathrm{CO} 2$ experimental results. Also, discrepancy between the calculated length of capillary tube for the separated flow and homogeneous flow models was around $2-7 \%$ in the same operating conditions. Moreover, when the coiled diameter increases from $40 \mathrm{~mm}$ to $600 \mathrm{~mm}$ that leads to the rate of mass flow for $\mathrm{CO} 2$ also increased around 7\%. García et al. [5] numerical simulated capillary tube behavior under pure and mixed flow considering metastable region. The numerical results were validated with available experimental results and the results shown good agreement. The results shown that when the critical pressure was higher than or equal to the outlet pressure the

This paper was recommended for publication in revised form by Regional Editor Mohammad Rahimi-Gorji

${ }^{1}$ Mechanical Engineering Department, Engineering college, Mustansiriyah University, Baghdad, Iraq

${ }^{*}$ E-mail address: basim.freegah@uomustansiriyah.edu.iq

Orcid id: 0000-0001-6731-8804, 0000-0002-8239-2380,0000-0003-3819-7008

Manuscript Received 06 January 2019, Accepted 03 March 2019 
flow was critical and discharge shock wave was solved. Also, the results revealed that the non-adiabatic and adiabatic capillary tubes working under transient, steady, non-critical or critical operating condition can be investigation using numerical method. Wongwises and Suchatawut [6] predicted the characteristics of refrigerant flow counting metastable area within the adiabatic capillary tube. The numerical model was validated with the experimental results stated in the literature. The average prediction of tube length error was around $1.52 \%$ as comrade to the literature. Also, the mass flow rate prediction error was around $2.41 \%$ for the R22 measured results. García [7] numerical simulated in the non-adiabatic capillary tubes with metastable area. The numerical simulation model permits to investigate different aspects for example type of fluid, geometry, transient cases, metastable regions, non-critical and critical flow operating conditions. The best agreement was obtained under two-phase frictional multiplier based on the literature. M. Heimel et al [8] used the ANN method to predict the performance of non-adiabatic capillary tubes for isobutene flow. Because of in literature most of the correlations calculation were not capable to predict mass flow rate for non-choked in two phase flow at inlet operation condition. Therefore, in their study the basis data found through homogeneous model has been validated by experimental data in literature. Using ANN technique can be to calculate non-choked and choked in two phase flow at inlet operating conditions. The range of mass flow rate in this work was from 0 to $5 \mathrm{~kg} / \mathrm{h}$, the inlet pressure was from saturation pressure to 10 bar. The superheating from $0 \mathrm{~K}$ to $30 \mathrm{~K}$ and sub cooling was from 0.7 to 0 . Václav Vinš [9] conducted the correlation of mass flow rate for two phases in the capillary tube. The experimental data was acquired for refrigerant R218 this type was used in many vapor cooling systems for example in different particle detectors. Mass flow rate analytical correlation for refrigerant R218 was derived by dimensionless parameters using Buckingham p-theorem approach. The author was compared between Two approaches the first one was conventional power law and the second one was correlation determined using ANN method. It was found that the ANN method can be utilized for approximating estimation of refrigerant mass flow rate for different refrigerants.

\section{MATHEMATICAL MODEL}

In order to analysis the model of capillary tube, some assumptions have been considered in the present study. Those assumptions are constant mass flow rate through the capillary tube, constant cross-sectional area along length of the capillary tube and adiabatic capillary tube.

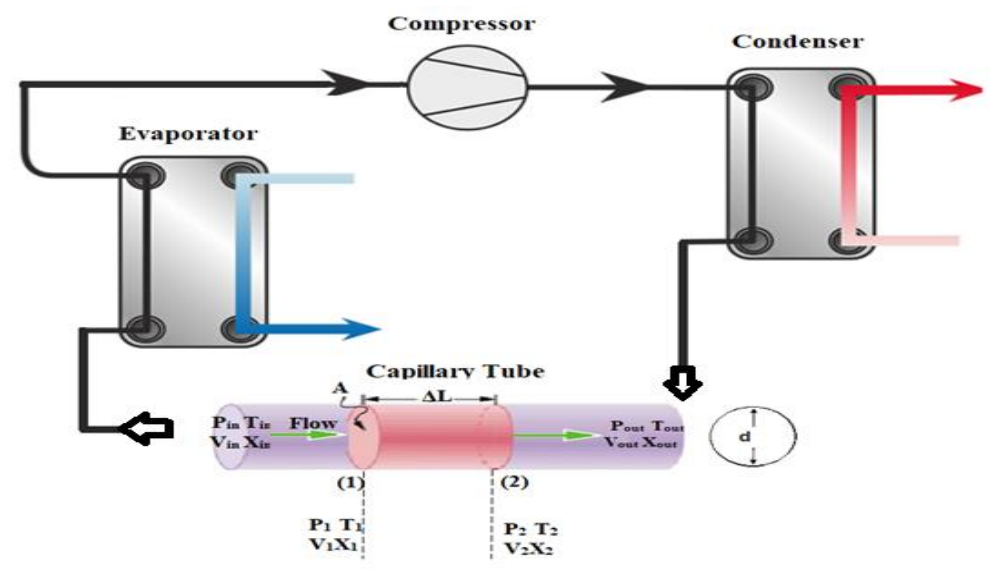

Figure 1. Schematic diagram of fluid flowing within the capillary tube

At steady state, since the mass flow rate (W) was assumed to be constant therefore the mass flow equation can be written as shown in equation (1).

$$
W=\left(\frac{V_{1} * A}{v_{1}}\right)=\left(\frac{V_{2} * A}{v_{2}}\right)
$$

and $(W / A)$ will be constant throughout the length of the capillary tube. Since an adiabatic condition was assumed in the capillary tube, then an energy equation can be written as shown in Equation (2), for a flow process.

$$
1000 * h_{1}+\left(\frac{V_{1}}{2}\right)^{2}=1000 * h_{2}+\left(\frac{V_{2}}{2}\right)^{2}
$$


While the momentum equation is given by equation (3).

$$
\left[\left(P_{1}-P_{2}\right)-f\left(\frac{\Delta L * V_{2} * 2 v}{d}\right)\right]=W *\left(V_{2}-V_{1}\right)
$$

Though, the enthalpy remains constant as a result of continuous flow of refrigerant (adiabatic situation) but there will be a progressive decrease in pressure. This results in refrigerant becoming tow-phase and hence the quality increases with capillary tube length. The enthalpy and humid volume depend on the dryness fraction (x). the required equations are given in Equation (4) and Equation (5), respectively.

$$
\begin{aligned}
& h=(1-X) * h_{f}+X * h_{g} \\
& v=(1-X) * v_{f}+X * v_{g}
\end{aligned}
$$

in equation (3) $\mathrm{V}, v$ and $f$ all change as the refrigerant flows from point 1 to point 2 , but some simplification results from equation 1 , which shows that $(\mathrm{V} / \mathrm{v})$ is constant so that:

$$
f\left(\frac{\Delta L}{d}\right)\left(\frac{V_{2}}{2 v}\right)=f\left(\frac{\Delta L}{d}\right)\left(\frac{v}{2}\right)\left(\frac{w}{a}\right)
$$

The velocity in equation 6 will be the mean velocity as shown:

$$
V_{m}=\frac{\left(V_{1}-V_{2}\right)}{2}
$$

The friction factor depends on Reynolds number and for Reynolds numbers in the lower range of the turbulent region an applicable equation for the friction factor is:

$$
f=\frac{0.33}{R e^{0.25}}=\frac{0.33}{\left(\frac{V \times d}{\mu \times v}\right)^{0.25}}
$$

The viscosity of the two-phase refrigerant at a given position in the tube is a function of the vapor fraction $(x)$ :

$$
\mu=(1-x) * \mu_{\mathrm{f}}+x * \mu_{\mathrm{g}}
$$

The mean friction factor $\left(f_{m}\right)$ applicable to the increment of length 1-2 is:

$$
f_{m}=\frac{\left(f_{1}-f_{2}\right)}{2}
$$

By combining of Equation (1) and Equation (2) we get:

$$
1000 h_{2}+\left(\frac{v_{2}{ }^{2}}{2\left(\frac{A}{W}\right)^{2}}\right)=1000 h_{1}+\left(\frac{V_{1}{ }^{2}}{2}\right)
$$

Substitute Eqs. (4) and (5) in to Equation (11)

$$
\begin{gathered}
\begin{array}{c}
\therefore \\
h_{2}=(1-X) * h_{f 2}+X * h_{g 2} \\
\mathrm{v}_{2}=(1-X) * \mathrm{v}_{f 2}+X * \mathrm{v}_{g 2}
\end{array} \\
1000 * h_{1}+\left(\frac{V_{1}}{2}\right)^{2}=1000 *\left[(1-X) * h_{f 2}+X * h_{g 2}\right]+\left(\frac{\left(\frac{W \mathrm{v}_{2}}{A}\right)}{2}\right)^{2} \\
1000 * h_{1}+\left(\frac{V_{1}}{2}\right)^{2}=1000 *\left[(1-X) * h_{f 2}+X * h_{g 2}\right]+\left(\frac{W}{2 A}\right)^{2}\left(\mathrm{v}_{2}\right)^{2} \\
1000 * h_{1}+\left(\frac{V_{1}}{2}\right)^{2}=1000 *\left[(1-X) * h_{f 2}+X * h_{g 2}\right]+\left(\frac{W}{2 A}\right)^{2}\left((1-X) * v_{f 2}+X * v_{g 2}\right)^{2} \\
1000 * h_{1}+\left(\frac{V_{1}}{2}\right)^{2}=1000 h_{f 2}-1000 X h_{f 2}+1000 X h_{g 2}+\left(\frac{W}{2 A}\right)^{2}\left(\mathrm{v}_{f 2}-X \mathrm{v}_{f 2}+X * \mathrm{v}_{g 2}\right)^{2} \\
1000 * h_{1}+\left(\frac{V_{1}}{2}\right)^{2}=1000 h_{f 2}+1000 X\left(h_{g 2}-h_{f 2}\right)+\left(\frac{W}{2 A}\right)^{2}\left(\mathrm{v}_{f 2}+X\left(\mathrm{v}_{g 2}-\mathrm{v}_{f 2}\right)\right)^{2}
\end{gathered}
$$


Now everything in Equation (12) is known except $(x)$, which can be solved by the quadratic equation:

$$
x=\mathrm{b}+\left(\frac{\left(\mathrm{b}_{2}-4 a c\right)^{\frac{1}{2}}}{2 a}\right)
$$

where,

$$
\begin{gathered}
a=\left(v \mathrm{~g}_{2}-v \mathrm{f}_{2}\right)^{2}\left(\frac{W}{A}\right)^{2} *\left(\frac{1}{2}\right) \\
\mathrm{b}=1000\left(\mathrm{hg}_{2}-\mathrm{hf}_{2}\right)+v \mathrm{f}_{2}\left(v \mathrm{~g}_{2}-v \mathrm{f}_{2}\right)\left(\frac{W}{A}\right)^{2} \\
\mathrm{c}=1000\left(\mathrm{hf}_{2}-\mathrm{h}_{2}\right)+\frac{1}{2} * v \mathrm{f}_{2}\left(\frac{W}{A}\right)^{2}-\left(\frac{v_{1}{ }^{2}}{2}\right)
\end{gathered}
$$

With the value of $(x)$ known $h_{2}, v_{2}$ and $V_{2}$ can be computed. Compute the Reynolds number at point (2) using the viscosity from Equation (9). The friction factor at point (2) from equation 8 and the mean friction factor for the increment from equation 10. Finally, by substituting Equation 6 and Equation 7 in Equation 3 we get $\Delta \mathrm{L}$.

\section{ARTIFICIAL NEURAL NETWORK (ANN) METHOD}

Recently, the artificial neural network has been widely applied in different field of engineering and it produces promising preliminary outcomes [10], due to the rapidly development in digital computers. Using ANN method for different applications are developing at a high impressive rate. The latter method is a computational technique inspired through the brain performance and systems of nervous in biological organisms. The ANN is presented in figure to show its terminology and basic structure. It can be shown from the figure this method consists of simple part named neurons in three main types of layers the first one is input layer and second one is hidden layer and finally output layer. Normally, each neuron in this network receives inputs from another neuron. There are two important types of statistical features in this method such as mean squared error and squared correlation coefficient. The statistical parameter squared correlation coefficient (R2) is more used in arbitrating regression equations [11].

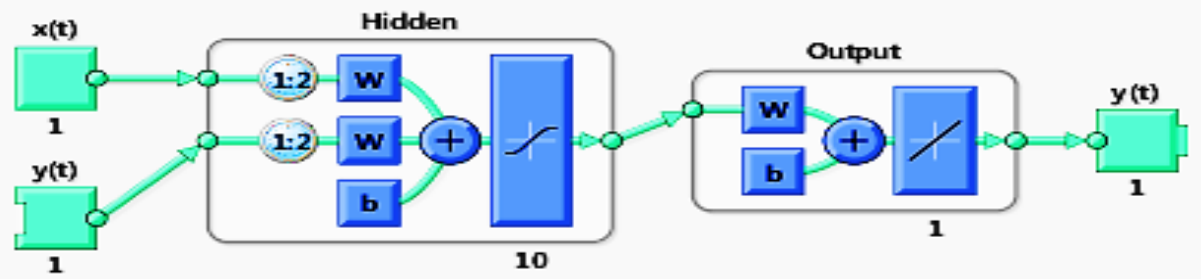

Figure 2. Typical artificial neural network method schematic diagram. The ANN has three different types of layers including input layer, hidden, and output layers

\section{RESULT AND DISCUSSION}

The diameters mutation and flow rates for liquid of refrigeration are using in this study were under varied conditions as follows, using $10 \mathrm{~kW}$ capacity refrigeration

1. Saturated condition of $\left(40^{\circ} \mathrm{C}\right)$ condensing temperature

2. Evaporation temperatures $\left(-5^{\circ} \mathrm{C}\right)$

3. The ambient temperature was assumed constant at $\left(35^{\circ} \mathrm{C}\right)$

4. Using liquid of refrigeration (R-22)

5. Varied the diameters of capillary tube $(\mathrm{d}=1.53,1.58$ and $1.63 \mathrm{~mm})$

6. Varied flow rates for liquid of refrigeration $(10,12$ and $14 \mathrm{~g} / \mathrm{s})$

\section{Validation}

The current numerical model is validated against the results of temperature and pressure of refrigerant (R22) along the capillary tub reported from literature [12]. Figure 3 shown the variation of (a) the refrigerant temperature along the capillary tube and (b) the variation of the refrigerant pressure along the length of capillary tube at the same boundary conditions. The boundary conditions were condensing temperature $26^{\circ} \mathrm{C}$ evaporation temperature $-7^{\circ} \mathrm{C}$, mass flow rate of refrigeration $15 \mathrm{~g} / \mathrm{s}$ and inner diameter of $2.16 \mathrm{~mm}$. The results have been shown a very good agreement between the present theoretical results and the experimental results, the length of capillary tube in the experimental case is $(2.223 \mathrm{~m})$ while in the theoretical case it is $(2.1329 \mathrm{~m})$ with most extreme deviation of $4 \%$. 


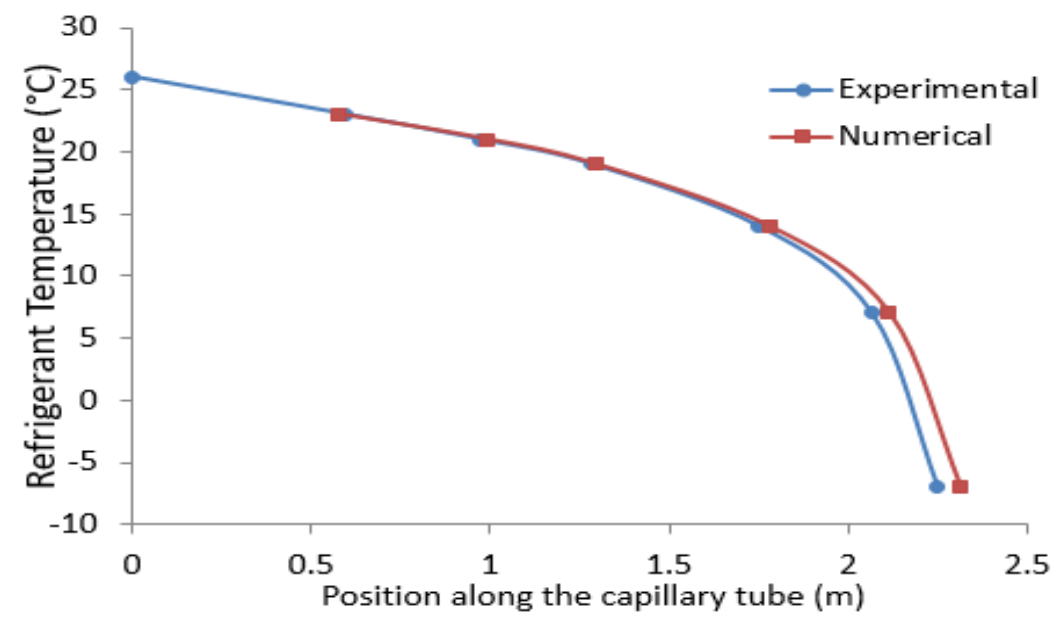

(a)

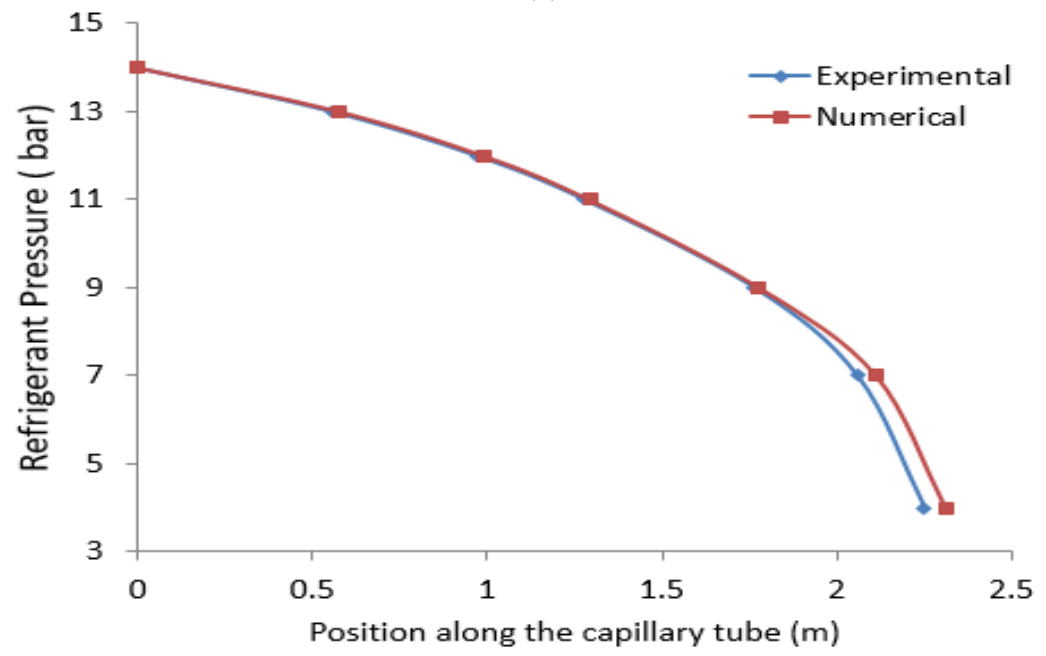

(b)

Figure 3. Validation of (a) refrigerant temperature and (b) refrigerant pressure along the capillary tube

\section{Simulation Results}

The effects of the physical properties of the refrigerant inside the capillary tube were studied for different diameters and mass flow rates. The studied properties include (pressure, temperature, velocity and the dryness index).

\section{The Impact of Diameter}

Figure 4, Figure 5 and Figure 6 show the variation capillary tube length for the refrigerant pressure, velocity of refrigerant and dryness index respectively at variables inner diameter. It can be clearly seen from Figure 4 that the change in capillary tube diameter has not effect on the refrigerant pressure within the capillary tube. Whiles, increase the diameter of capillary tube that lead to decrease of refrigerant velocity for percentage $(5.4 \%)$ when percentage reduce of diameter is (3\%) as shown in Figure 5. Furthermore, Figure 6 shows that increase the diameter of capillary tube with percentage $(3 \%)$ leads decrease the dryness factor with percentage $(1.2 \%)$. In addition, it can be clearly seen from all figures (Figure 4, Figure 5 and Figure 6) that increase the diameter of capillary tube leads to increase in capillary tube length. Increases diameter from $(1.58 \mathrm{~mm}$ to $1.63 \mathrm{~mm})$ gives increment length about $(0.25 \mathrm{~m})$. it can be say that percentage increases for diameter $(3 \%)$ leads to percentage increase length $(16 \%)$. It can be concluded that the diameter of capillary tube has effect on the length of capillary tube. 
Journal of Thermal Engineering, Research Article, Vol. 7, No. 3, pp. 690-699, March, 2021

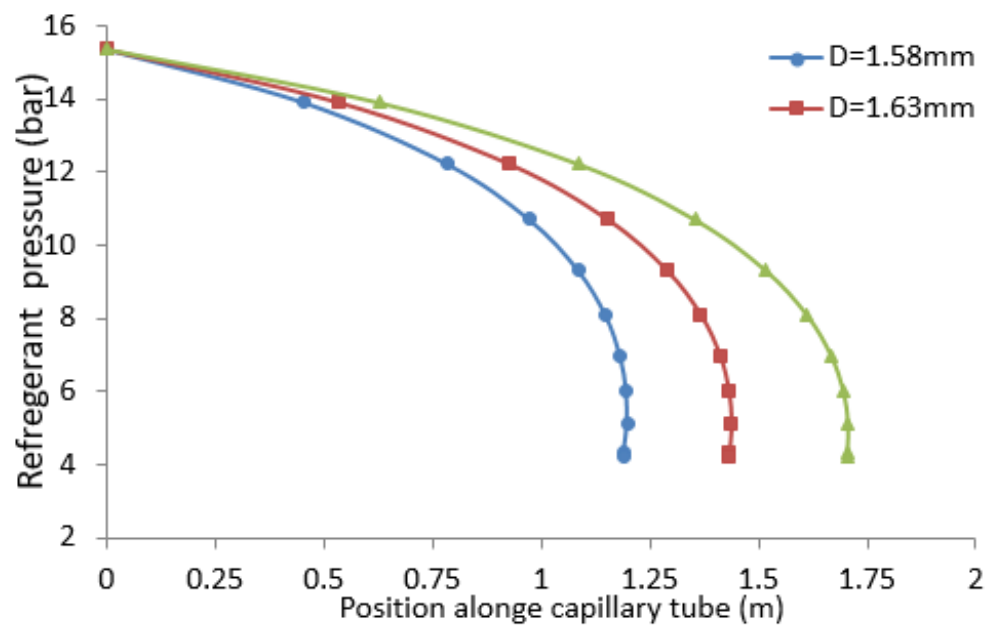

Figure 4. Refrigerant pressure variation along capillary tube length for variables diameter of capillary tube

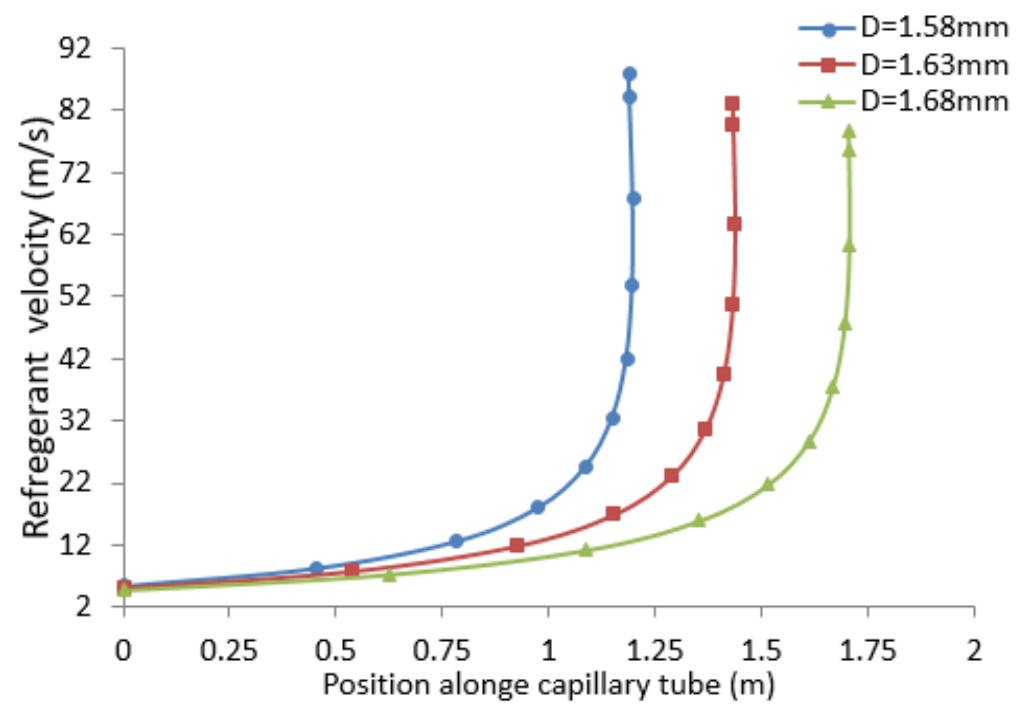

Figure 5. Refrigerant velocity distribution along capillary tube length for variables diameter of capillary tube

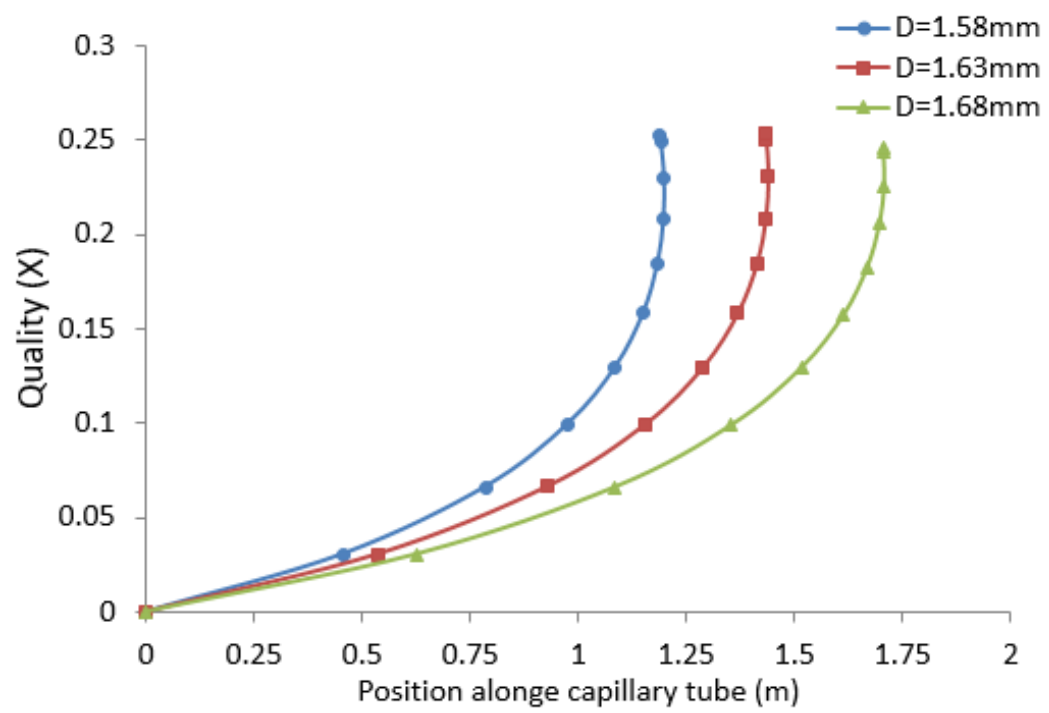

Figure 6. Dryness index of refrigerant within the along capillary tube length for variables diameter of capillary tube 


\section{The Impact of Mass Flow Rate}

The variation of the refrigerant pressure, velocity of refrigerant and dryness index along the length the capillary tube at variables of mass flow rate show in Figure 7, Figure 8 and Figure 9. It can be clearly seen from Figure 7 that the change in mass flow rate of refrigerant has not effect on the refrigerant pressure within the capillary tube. Whiles, increase the mass flow rate lead to increase of refrigerant velocity for percentage $(15 \%)$ when percentage reduce of diameter is (14\%) as shown in Figure 8. Furthermore, Figure 9 shows that change in the mass flow rate has not effect on the dryness factor. In addition, it can be clearly seen from all figures (Figure 7, Figure 8 and Figure 9) that increase the mass flow rate leads to decrease in capillary tube length. Because an increase the mass flow rate leads to increase each of friction, the specific volume, and velocity within the capillary tube. Hence, decrease the pressure drop that leads to decrease the length of capillary tube. Increases mass flow rate from $(12 \mathrm{~g} / \mathrm{s}$ to $14 \mathrm{~g} / \mathrm{s})$ gives decrease in length about $(0.7 \mathrm{~m})$. It can be say that percentage increases for mass flow rater $(15 \%)$ leads to percentage decrease length (33\%). It can be concluded that the mass flow rate of the refrigerant has effect on the length of capillary tube.

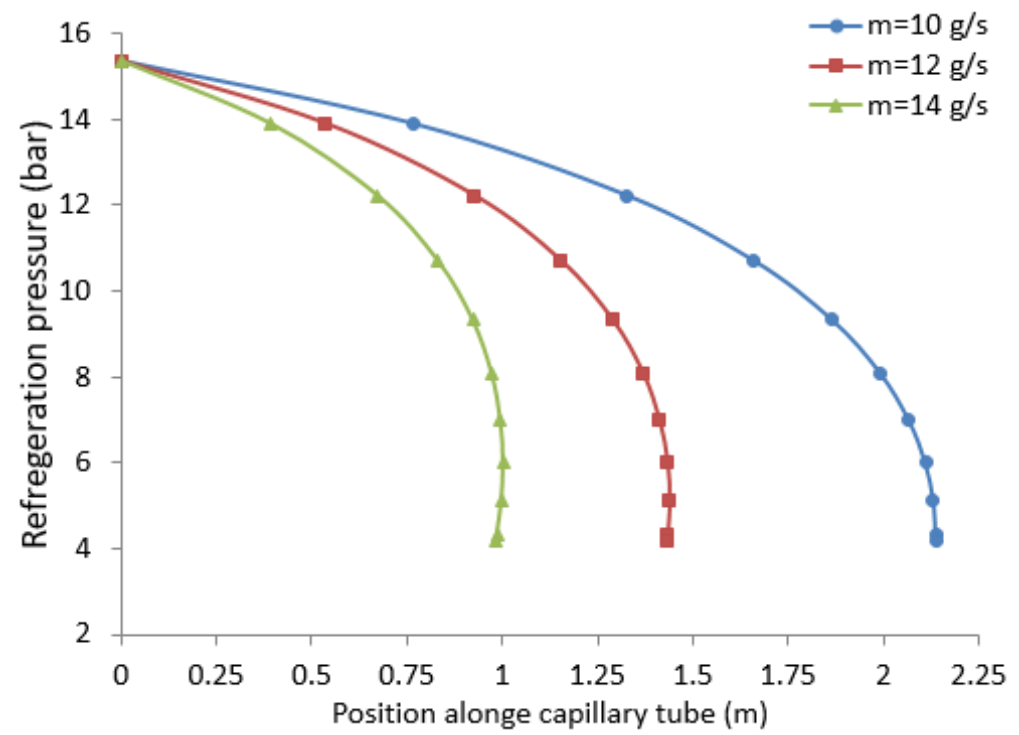

Figure 7. Refrigerant pressure variation along capillary tube length for variables mass flow rate

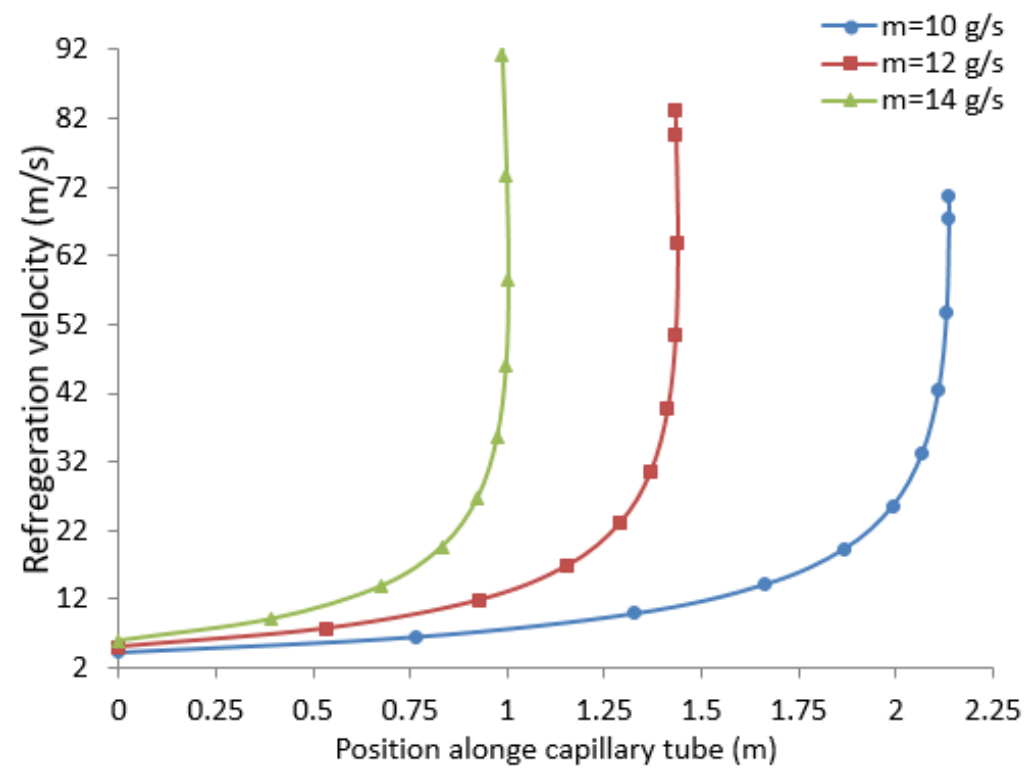

Figure 8. Refrigerant velocity distribution along capillary tube length for variables mass flow rate 


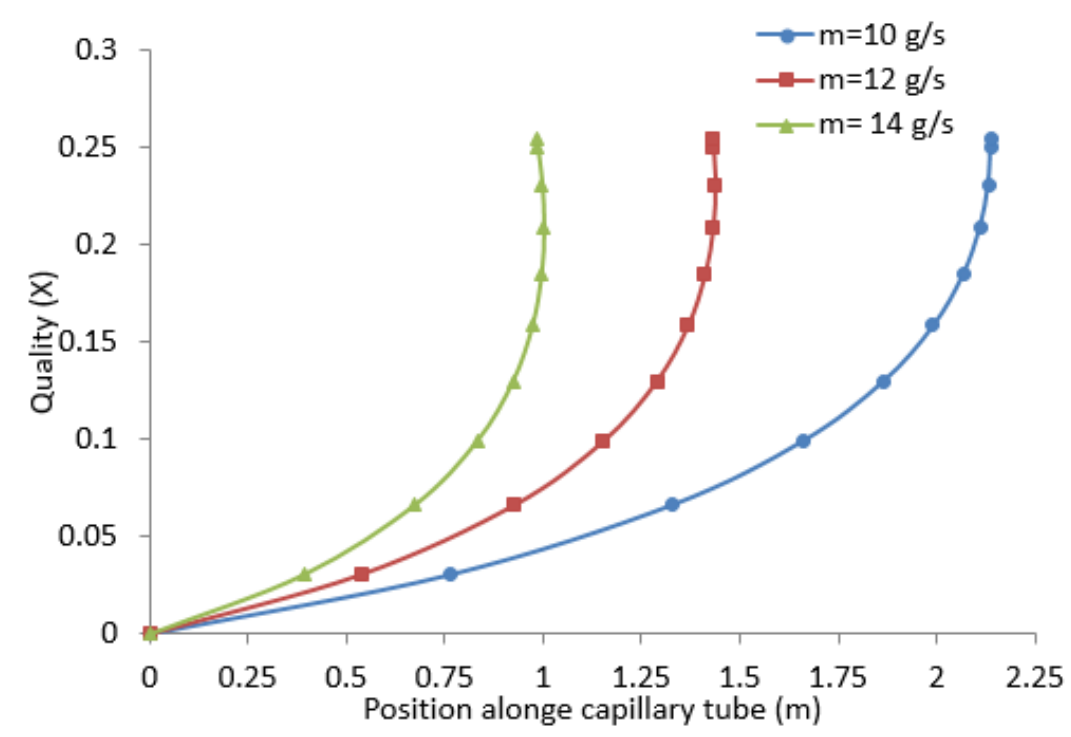

Figure 9. Dryness index of refrigerant within the along capillary tube length for variables mass flow rate

\section{The Artificial Neural Network (ANN)}

In this work, an ANN technique to predict of flow behavior of refrigerant within the capillary tube was put to test. Thus, in this investigation the calculation attained data set have been used. Figure 10 depicts the designed learning process of the Artificial Neural Network (ANN) respect to the time evolution. It can be seen that when repeated epochs the value of MSE monotonically decreases for all results such as test, training, and validation data. It can be seen that the mean square error does not change with number of elements (epochs number) that mean no more value of training data is needed. Moreover, a neural network is stopped training when the error, i.e., the difference between the desired output and the expected output is below some threshold value or the number of iterations or epochs is above some threshold value Also, the proposed Artificial Neural Network has a good performance in predicting and modeling the capillary tube and the percentage error was about 5\% as shown in Figure 11.

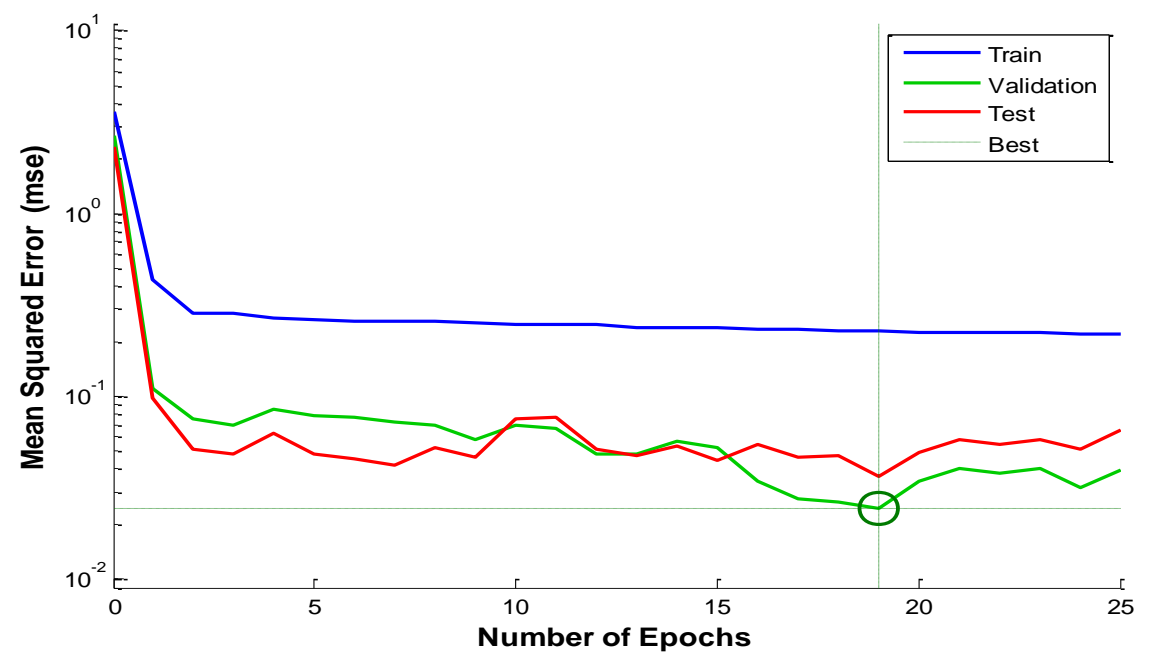

Figure 10. Shows MSE value against the epochs number for test data, training data, and validation data using ANN technique 

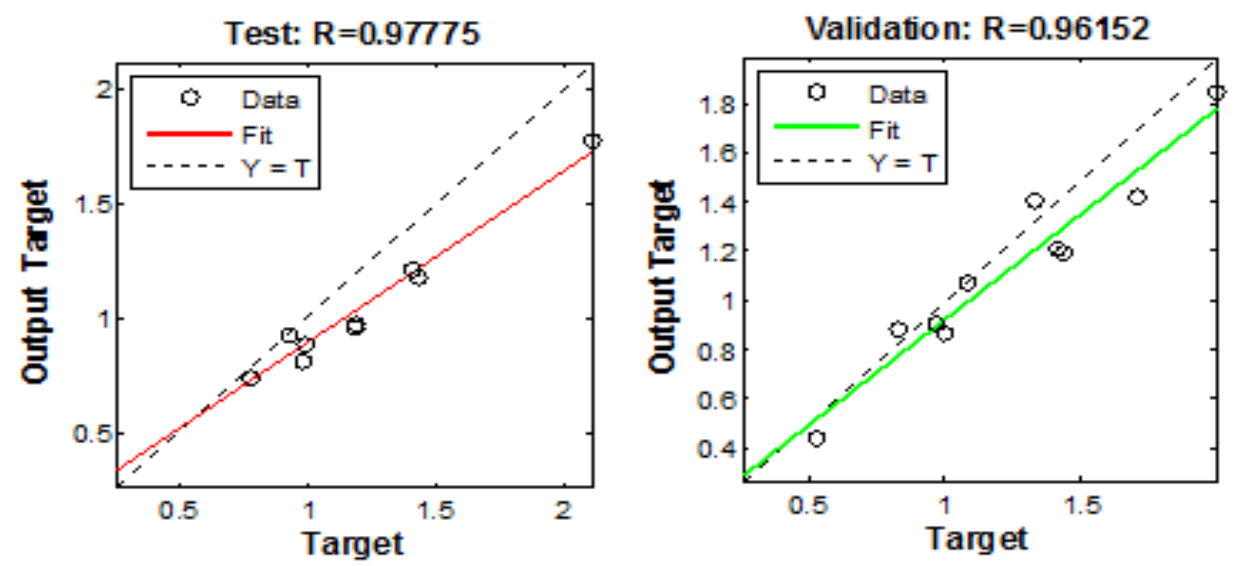

Figure 11. The percentage error for output target using ANN technique

\section{CONCLUSION}

The effects of various parameters, such as diameter of capillary tube and mass flow rate of refrigerant have been investigated numerically. It can be concluded the following:

1- When is the diameter of capillary tube is constant and increase mass flow rate of refrigerant that lead to:

- Decrease in capillary tube length for example increase the mass flow rate of refrigerant for percentage (9\%) that lead the capillary tube length will be decrease for percentage (18.5\%).

- No change for the dryness index.

- Increase in the Refrigerant velocity for percentage (8.3\%).

2- When mass flow rate of refrigerant is constant and increase diameter of capillary tube that lead to:

- Increase in capillary tube length for example increase the percentage $(3.16 \%)$ that lead the capillary tube length will be increase for percentage (15\%)

- Decrease for the dryness index for percentage (3\%)

- Decrease in the Refrigerant velocity for percentage (5.4\%).

3- Using ANN technique for studying the effect of capillary tube diameter and mass flow rate on the length of capillary shown that this technique has a good performance in predicting and modeling the capillary tube. Moreover, the percentage error using latter technique was around $5 \%$.

\section{ACKNOWLEDGEMENT}

The authors would like to thank Mustansiriyah University (www.uomustansiriyah.edu.iq) in Baghdad - Iraq for its support in the present work.

\section{NOMENCLATURE}

A Cross section area of capillary tube, $\mathrm{m}^{2}$

$\mathrm{d}$ Inner diameter of tube capillary tube, $\mathrm{m}$

$\mathrm{f} \quad$ Friction factor, dimensionless

$\mathrm{h} \quad$ Enthalpy, $\mathrm{kJ} / \mathrm{kg}$

$\Delta \mathrm{L} \quad$ Length of increment, $\mathrm{m}$

$\mathrm{k} \quad$ Thermal conductivity, $\mathrm{W} / \mathrm{m}{ }^{\circ} \mathrm{C}$

P Pressure, ps

Re Reynolds number, dimensionless

$\mathrm{V} \quad$ Velocity of refrigerant, $\mathrm{m} / \mathrm{s}$

W Mass flow rate, $\mathrm{kg} / \mathrm{s}$

$\mathrm{X} \quad$ Dryness fraction, dimensionless

Greek symbols

u Specific volume, $\mathrm{m}^{3} / \mathrm{kg}$

$\mu \quad$ Viscosity, $\mathrm{Pa} * \mathrm{~S}$ 
Journal of Thermal Engineering, Research Article, Vol. 7, No. 3, pp. 690-699, March, 2021

$\begin{array}{ll}\text { Subscripts } & \\ 1 & \text { Inlet } \\ 2 & \text { Outlet } \\ \mathrm{f} & \text { Liquid } \\ \mathrm{g} & \text { Vapor } \\ \mathrm{m} & \text { Mean }\end{array}$

\section{REFERENCES}

[1] Sainath, Kasuba, T. Kishen Kumar Reddy, and Suresh Akella. "Optimization of capillary tube dimensions using different Refrigerants for 1.5 ton mobile air conditioner." Case Studies in Thermal Engineering 16 (2019): 100528. https://doi.org/10.1016/j.csite.2019.100528.

[2] Ajayi, Oluseyi O., Dorothy E. Ibia, Mercy Ogbonnaya, Ameh Attabo, and Agarana Michael. "CFD analysis of nanorefrigerant through adiabatic capillary tube of vapour compression refrigeration system." Procedia Manufacturing 7 (2017): 688-695. https://doi.org/10.1016/j.promfg.2016.12.102.

[3] Mittal, M. K., Ravi Kumar, and Akhilesh Gupta. "Numerical analysis of adiabatic flow of refrigerant through a spiral capillary tube." International Journal of Thermal Sciences 48, no. 7 (2009): 1348-1354. https://doi.org/10.1016/j.ijthermalsci.2009.01.003.

[4] Wang, Jing, Feng Cao, Zhizhong Wang, Yuanyang Zhao, and Liangsheng Li. "Numerical simulation of coiled adiabatic capillary tubes in $\mathrm{CO} 2$ transcritical systems with separated flow model including metastable flow." International journal of refrigeration 35, no. $8 \quad$ (2012): 2188-2198. https://doi.org/10.1016/j.ijrefrig.2012.07.012.

[5] Garcia-Valladares, O., C. D. Perez-Segarra, and A. Oliva. "Numerical simulation of capillary-tube expansion devices behaviour with pure and mixed refrigerants considering metastable region. Part II: experimental validation and parametric studies." Applied thermal engineering 22, no. 4 (2002): 379-391. https://doi.org/10.1016/S1359-4311(01)00097-7.

[6] Wongwises, Somchai, and Mathurose Suchatawut. "A simulation for predicting the refrigerant flow characteristics including metastable region in adiabatic capillary tubes." International journal of energy research 27, no. 2 (2003): 93-109. https://doi.org/10.1002/er.860.

[7] García-Valladares, O. "Numerical simulation of non-adiabatic capillary tubes considering metastable region. Part I: Mathematical formulation and numerical model." International Journal of Refrigeration 30, no. 4 (2007): 642-653. https://doi.org/10.1016/j.ijrefrig.2006.08.015.

[8] Heimel, Martin, Wolfgang Lang, and Raimund Almbauer. "Performance predictions using Artificial Neural Network for isobutane flow in non-adiabatic capillary tubes." International journal of refrigeration 38 (2014): 281-289. doi.org/10.1016/j.ijrefrig.2013.08.018.

[9] Vinš, Václav, and Václav Vacek. "Mass flow rate correlation for two-phase flow of R218 through a capillary $\begin{array}{llllll}\text { tube." Applied thermal engineering 29, no. } & \text { 2816-2823. }\end{array}$ https://doi.org/10.1016/j.applthermaleng.2009.02.001.

[10] Islamoglu, Yasar, Akif Kurt, and Cem Parmaksizoglu. "Performance prediction for non-adiabatic capillary tube suction line heat exchanger: an artificial neural network approach." Energy conversion and management 46, no. 2 (2005): 223-232. https://doi.org/10.1016/j.enconman.2004.02.015.

[11] Duch, Włodzisław. "Coloring black boxes: visualization of neural network decisions." In Proceedings of the International Joint Conference on Neural Networks, 2003., vol. 3, pp. 1735-1740. IEEE, 2003. https://doi.org/10.1109/IJCNN.2003.1223669.

[12] Stoecker, W. F., and W. N. Jones. "Refrigeration and Air Conditioning. The McGaw-Hill." Inc. New York (1982). 